\title{
Comparison the Formation of Spark Corona Discharge between Tap and distilled Waters at Liquid Electrode System
}

\author{
Qusay A. Abbas" ${ }^{*} \quad$ Majid H. Dwech** \\ Fadhil Y. Hadi " Falah A-H.Mutlak ${ }^{*}$
}

Received 29,February,2012

Accepted 16,October,2012

\begin{abstract}
:
In this paper, we studied the spark corona discharge in tap and distillited waters. The results show the shape of cone that generated on the tip of capillary tube is different with conductivity of liquids. The blue glow appears at the end of capillary tube and the drop extends into a cone. In addition, the conducitivity is affected on the relationship between the appearance of the blue glow discharge with the applied voltage. The size of the cone decreases with an increase in applied voltage. The cone diameter at the base of capillary tube oscillates with period approximately $1 \mathrm{Sec}$. this oscillates in the cone diameters is due to the change distance between the liquid electrode and the surface of liquid. The intensity of spark corona discharge that formed in tap water higher than that formed in distillited water. In addiation, when the applied voltage is $5 \mathrm{KV}$ on distillted water, the drope extends into two cones while in tap water the drop extends into one cone. These contrast between two water types which under test (i.e. tap and distillited waters) is due to the differance in condictivity of water.
\end{abstract}

Keywords: Corona discharge, liquid discharge, Tap water, Distilled water.

\section{Introduction:}

Plasma is ionized gases which consists of positive and negative ions, and electrons as well as neutral species. The plasma state is regarded the fourth state of matter. In general, plasmas are classified into two kinds: thermal equilibrium plasma and nonthermal equilibrium plasma. Thermal equilibrium implies that the temperatures of all species, including electrons, ions and neutral species are the same. On the othere hand, nonthermal equilibrium means that the temperatures of the different plasma species are not the same. More precisely, the electrons are characterized by much higher than temperatures than the heavy particles (ions, atoms, molecules) [1]. Nonthermal plasma can drive high- temperature chemistry at low ambient temperatures using input energy levels that are lower than the energy required for driving an equilibrium reaction. The wide variety of chemical non-equilibrium coniditions are possible in which parameters can easily be modified by external control, such as chemical input, pressure, electromagnetic field structure, discharge configration, and tomporal behavior. Due to this multidimenstional parameter space of the plasma conditions, plasma are employed in a number of applications, such as plasma spectra-chemistry, cutting, spraying, welding, etching or deposition of thin layers and catalysis [1-3]. Recently, electrical discharge in liquids have received particular 
attention because the nonthermal plasma generated by these discharges initiate various chemical and physical processes that can be potentially utilized in different environmental, biological, or medical application. Depending on the type of the discharge and the input energy, these processes include high electric field, ultraviolet radiation, and overpressure shock wave are of particular importance[4]. Understanding the properties of the water is essential for a wide range of physical and biological processes, and is a key point in many areas of technological development. A number of the thermodynamics and transport properties of liquid water exhibit unusual behavior, especially at low temperture [5]. In the supercooled regime below the melting point, the behavior of water, seems to indicate that there is a singular temperture at which various thermodynamic response functions and transport properties diverge. Scientists have long sought a coherent explanation for this behavior [5-7]. A second and related puzzle currently being debated concerns how one determines the virification temperture of supercooled water $[5,8]$.

\section{Materials and Methods:}

Figure (1) shows a schematic view of the apparatus used in this study. The apparatus consisted of a glass vessel 1 of $250 \mathrm{~cm}^{3}$ in volume, which is filled with $150 \mathrm{~cm}^{3}$ of a liquid to be treated. The liquids which treated in this work are tap and distilled waters. The glass vessel had a rubber head 2 with a fixed electrode 3 and glass tube 4 of $2 \mathrm{~mm}$ in inner diameter: at the end of glass tube, glass capillary tube 6 of $0.12 \mathrm{~mm}$ in inner diameter was fastened. Above the head, reserve feed container 5 of $150 \mathrm{~cm}^{3}$ in volume for an electrode liquid was mounted on capillary tube 6. A corona discharge was excited in air between the surface of liquid and liquid electrode. From a d.c. power supply 8 was applied to the liquid in the vessel container through ballast resistor 7 with a resistance of $2 \mathrm{M} \Omega$. To run the experiment, liquids (tap water and distilled water) from a container 5 were sucked into tube 4 and capillary tube 6 with a rubber bulb. The length of capillary 6 was $4.5 \mathrm{~cm}$ and that of tube 4 was $2 \mathrm{~cm}$. the distance between the capillary end and the liquid surface was maintained at about $1 \mathrm{~cm}$. 


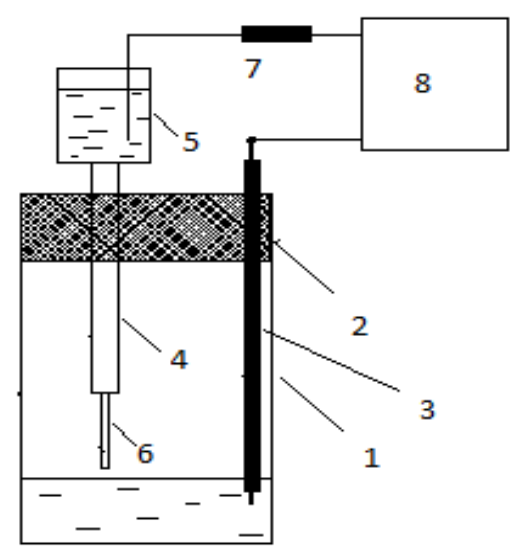

Fig.(1): Schematic of the experimental set up: 1) Glass reaction vessel,2) The glass vessel had a rubber head, 3) fixed electrode, 4) Glass tube, 5) container for the electrode liquid, 6) glass capillary tube, 7) ballast resistor, and 8) d.c. power supply.

\section{Results and Discussions:}

The processes occurring at the tip of the capillary are illustrated in figures (2) and (3) which present photographs of the electrode at various voltages for different water types. It is clear from these figures, in the absence of the voltage, a drop is formed at the tip, which increases to large dimensions and falls. When the voltage is applied, the drop diameter increases, and the drop extends along the electrode axis. When the voltage $2 \mathrm{KV}$ is applied, a blue glow appears at the end of the capillary tube and the drop extends into a cone. The size of the cone decreases with the increase of the applied voltage. As well as, the cone diameter at the base of capillary tube oscillates with period approximately 1 Sec. this oscillate in the cone diameters is due to the change distance between the liquid electrode and the surface of liquid. This behavior was shown in both waters.Piskarev et.al. [9] showed the same results Electrical conductivity is a measure of the ability of a solution to carry a current. Current flow in liquids differs from that in metal conductors in that electrons cannot flow freely, but must be carried by ions. Ions are formed when a solid such as salt is dissolved in a liquid to form electrical componentshaving opposite electrical charges. Generally, since the tap water and distilled water are different in conductivity (where the measured electrical conductivity of tap and distilled waters is $30 \mu \mathrm{hm} / \mathrm{cm}$ and $18 \mu \mathrm{hm} / \mathrm{cm}$,respectivly), so there are some different results can be see between both figures. The difference between both water types are: the tap water showed high intensity discharge between the liquid electrodes. The shape of the cone that generated at the tip of capillary tube is different too. 


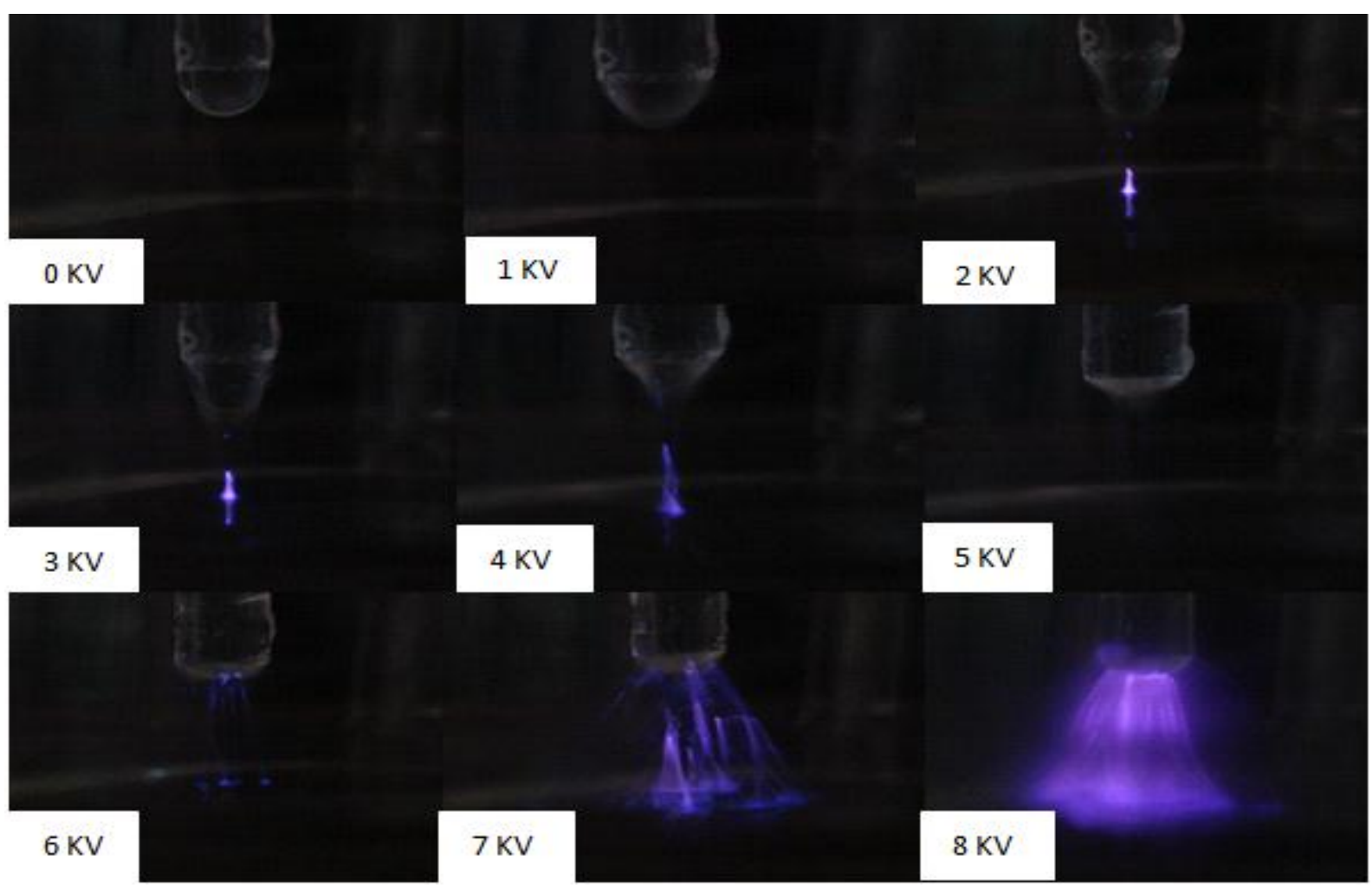

Fig.(2): Photograph of the tap water electrode without applied voltage and under different voltages.

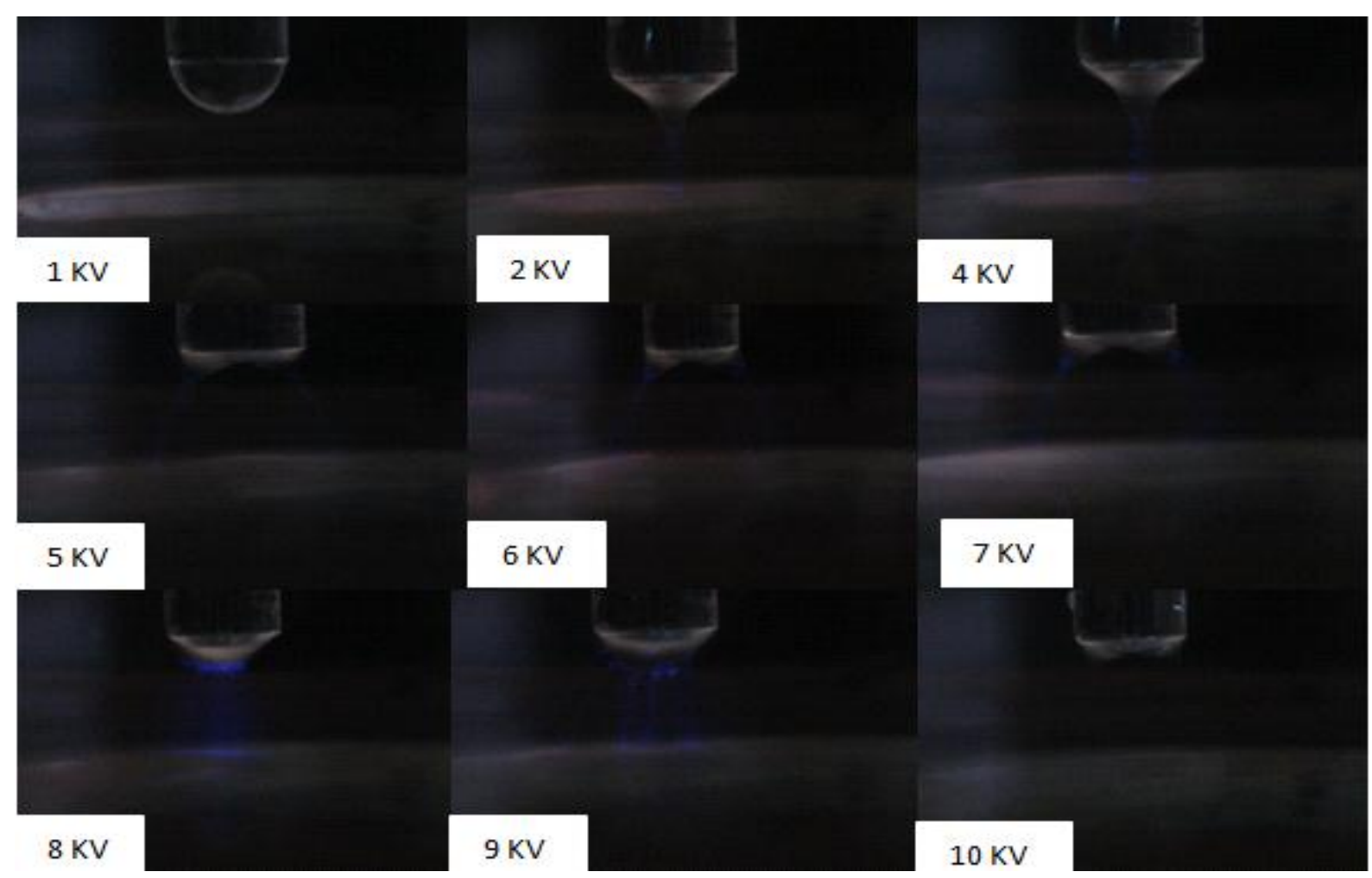

Fig.(3): Photograph of the distilled water electrode without applied voltage and under different voltages. 
In this paper, we stuided the spark corona discharge that is formed between two liquid electrodes in the tap and distilled waters. The results showed that the shape of cone that generated on the tip of capillary tube is different with conductivity of liquids. The blue glow appears at the end of capillary tube and the drop extends into a cone. In addition, the conducitivity is affected on the relationship between the appearance of the blue glow discharge with the applied voltage. The size of the cone decreases with an increase in applied voltage. The cone diameter at the base of capillary tube oscillates with period approximately $1 \mathrm{Sec}$. this oscillate in the cone diameters is due to the change distance between the liquid electrode and the surface of liquid. The intensity of spark corona discharge that formed in tap water is higher than that formed in distilled water. In addiation, when the applied voltage is $5 \mathrm{KV}$, the drope extends into two cones.

\section{References:}

1. Zong-cheng Y., Li C., and Hong-lin W., 2006,Experimental Study of Plasma Under-Liquid Electrolysis in Hydrogen Generation, CHINESE J. PROC. ENGINEER., 6 (3), 396-401.

2. Chen J.R., 2001, Low Temperature Plasma Chemistry and Its Application [M],Beijing Science Press, 1-40 (IN Chinese).

3. Bai X.Y., Zhang Z. T., and Bai M. D., 2002, The Study State and Progress of
Non-equilibrium Plasma Chemistry [J], Chin Sci. Bull., 47(5)321-322 (in Chinese).

4. Lukes P., Member, 2008, Pulsed Electrical Discharge in Water Generated Using Porous-CeramicCoated Electrodes, IEEE TRANSACTIONS PLASMA SCIENCE, 36(4), 1146-1147.

5. Mallamace F., Branca C., Corsaro C., Leone N., Spooren J., Stanley H., and Chen S.-H., 2010, Dynamical Crossover and Breakdown of the Stokes-Einstein Relation in Confined Water and in Methanol-Diluted Bulk Water, J. Physics Chemistry B, 114,1870-1878.

6. Kumar P., Stanley H.E., 2011, Thermal Conductivity Minimum: A new water Anomaly,the Journal of Physical Chemistry B, 115,14269-14273.

7. Mishima O., Stanley H. E., 1998, The relationship Between Liquid, Supercooled and Glassy Water, Nature, 396, 329-335.

8. Velikov V.,Borick S., and Angell C.A., 2001, The glass transition of water, based on hyperquenching experiments,Science, 294,2335.

9.Piskarev I. M., Solov G.G., Karelin V.I., Selemir V.D., and Spirov G.M., 2005,Formation of Active Species in Spark Corona Discharge at a Liquid Electrode,High Enery Chemistry,39(3), 189-191. 


\title{
المقارنة بين تكوين التوهج الاهليلي النبضي لماء الحنفية والماء المقطر لمنظومة

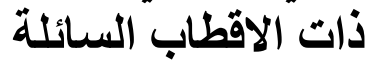

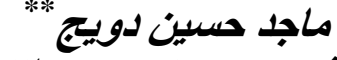

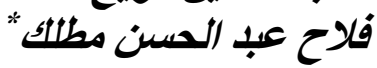

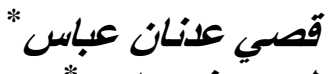

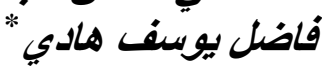 \\ *ققم الفيزياء, كلية العلوم, جامعة بغداد, بغداد, العراق.

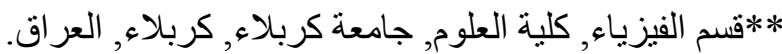

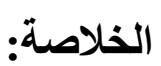

في هذا البحث,تم در اسة التفريغ الاهليلي النبضي المتكون في ماء الحنفية و الماء المقطر. ان النتائج

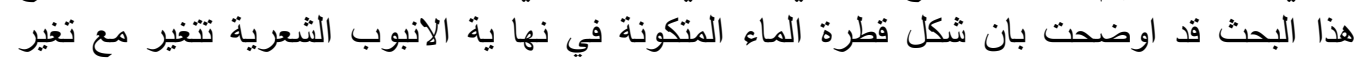

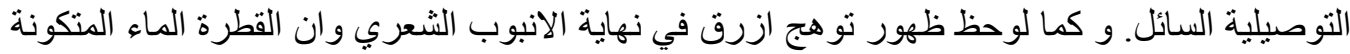

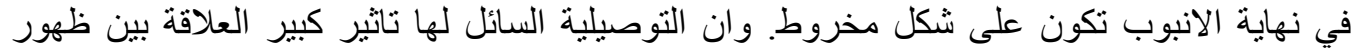

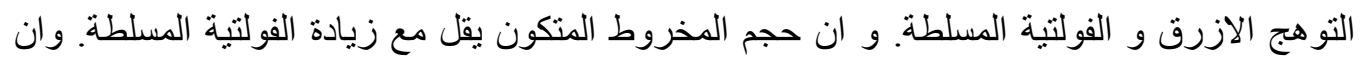

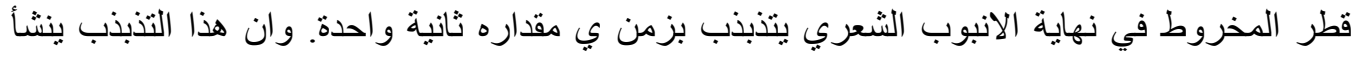

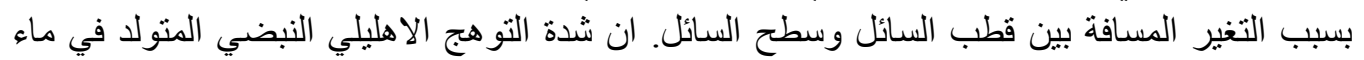

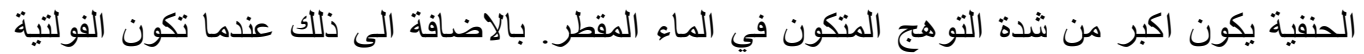

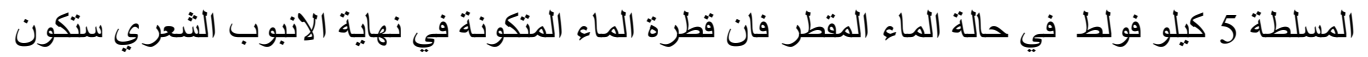

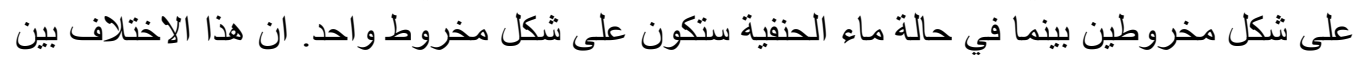
كلا نو عين من الماء يعزى الى الاختلاف التوصيلية بين كلا نو عين من الماء.
\end{abstract}

